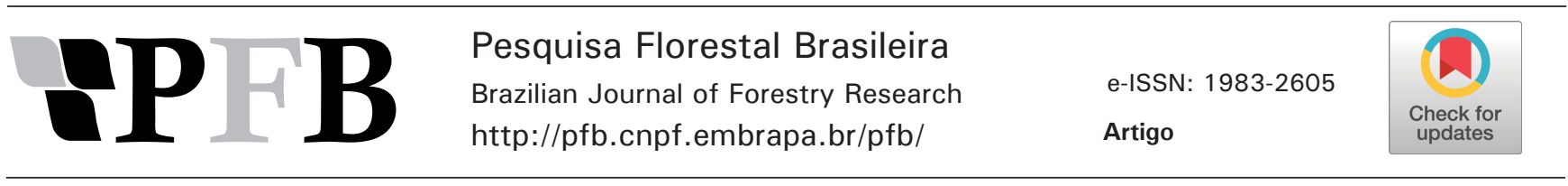

\title{
Técnica de realocação de Rhipsalis (Cactaceae) em florestas regenerantes, em Itaboraí - RJ: sobrevivência e desenvolvimento
}

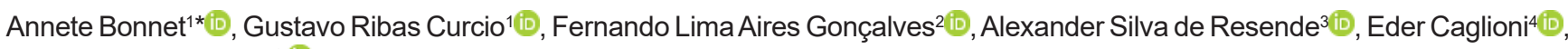 \\ Osmir José Lavoranti ${ }^{1}$ (D)
}

${ }^{1}$ Embrapa Florestas, Estrada da Ribeira, km 111, CP. 319, CEP 83411-000, Colombo, PR, Brasil

2Universidade Federal Rural do Rio de Janeiro, Rodovia BR-465, km 7, CEP 23890-000, Seropédica, RJ, Brasil

${ }^{3}$ Embrapa Agrobiologia, Rodovia BR-465, km 7, CEP 23891-000, Seropédica, RJ, Brasil

${ }^{4}$ Sociedade Educacional Leonardo da Vinci, BR-470, km 71, n 1040, CEP 89084-405, Indaial, SC, Brasil

"Autor correspondente:

annete.bonnet@embrapa.br

Termos para indexação:

Enriquecimento

Epífitos vasculares

Restauração ecológica

Index terms:

Enrichment

Vascular epiphytes

Ecological restoration

Histórico do artigo:

Recebido em 19/11/2019

Aprovado em 24/04/2020

Publicado em 28/08/2020
Resumo - Este estudo teve por objetivo avaliar a sobrevivência e o desenvolvimento de cactáceas epifíticas Rhipsalis lindbergiana K. Schum. e $R$. pachyptera Pfeiff. Fragmentos foram acompanhados em casa de vegetação durante quatro meses em diferentes substratos e após realocação para Floresta Ombrófila Densa em regeneração, município de Itaboraí, RJ. A realocação foi acompanhada por até três anos e realizada em dois períodos climáticos: menor (lote da seca) e maior precipitação (lote de chuva). Registrou-se maior crescimento das duas espécies em substrato com matéria orgânica. Os lotes da seca foram significativamente distintos nas duas espécies, provavelmente em função das chuvas que se sucederam e possibilitaram maior sobrevivência e desenvolvimento. A sobrevivência e desenvolvimento de $R$. lindbergiana apresentaram relação significativa com a altura das árvores onde os fragmentos foram instalados, remetendo à associação existente entre elevada diversidade de epífitos com grandes forófitos. Recomenda-se a realocação de epífitos em árvores maiores, no início dos períodos chuvosos e mantendo os fragmentos em contato com o substrato. Isso possibilitará melhor aproveitamento das plantas, além de impulsionar os processos de recuperação da diversidade e funcionalidade ecológica das florestas.

\section{Rhipsalis (Cactaceae) relocation technique in regenerating forests, Itaboraí, Rio de Janeiro, Brazil: survival and development}

\begin{abstract}
This study aimed to evaluate survival and development of epiphytic cactus Rhipsalis lindbergiana K. Schum. and R. pachyptera Pfeiff. Fragments were monitored in a greenhouse, for four months on different substrates and after relocation to regenerating Ombrophilous Dense forest, in Itaboraí, Rio de Janeiro, Brazil. The relocation was monitored for up to three years and carried out in two climatic periods: lower (drought plot) and higher precipitation (rainfall plot). Higher growth of both species was registered in substrate with organic matter. Drought plots were significantly different in both species, probably due to the rains that followed the dry season and allowed greater survival and development. The survival and development of $R$. lindbergiana were significantly related to tree height where the fragments were installed, referring to the association between high epiphyte diversity and large phorophytes. It is recommended to relocate epiphytes to larger trees, at the beginning of the rainy season and keeping the fragments in contact with the substrate. This will enable the better use of plants, as well as the promotion of the recovery of forests diversity and ecological functionality processes.
\end{abstract}




\section{Introdução}

Epífitos vasculares são plantas que utilizam outras plantas como suporte, sobrevivendo durante toda sua vida, ou parte significativa dela, sobre árvores, arvoretas, cipós ou xaxins. São responsáveis por grande parcela da diversidade de florestas tropicais (Gentry \& Dodson, 1987; Nieder et al., 2001), além de ofertarem, nestes ambientes, água, nutrientes, microhábitats, abrigo, alimentação e sítio de reprodução para inúmeras espécies animais e vegetais (Rocha et al., 2004), o que as torna elemento chave para numerosas interações entre espécies.

No Brasil, o resgate de epífitos é prática exigida pelos órgãos ambientais estaduais, com base na Instrução Normativa $\mathrm{n}^{\circ}$ 6, de 7 de abril de 2009 (IBAMA, 2009), nos casos de desmatamentos realizados em grandes empreendimentos, como construção de hidrelétricas, linhas de transmissão, rodovias e atividades de mineração. É no Projeto Básico Ambiental (PBA), elaborado pelo empreendedor, que devem constar os programas e projetos que visam prevenir, corrigir e compensar os impactos ambientais (Milaneze-Gutierre et al., 2017), dentre eles, o resgate da flora.

No entanto, poucos métodos foram desenvolvidos, testados e discutidos no que se refere à retirada dos epífitos das florestas que são suprimidas, ou seja, existe uma escassez de pesquisas que preencham esta lacuna (Jasper et al., 2005; Jakovac et al., 2007; Santos Junior \& Tamaki, 2014; Milaneze-Gutierre et al., 2017), sobretudo técnicas de realocação em coerência aos distintos potenciais e fragilidades das espécies. É comum deparar-se com plantas resgatadas de florestas que acabam permanecendo em estufas, sendo doadas para particulares, e até sucumbindo antes de retornar aos ambientes naturais devido à falta de iniciativa das empresas responsáveis, falta de fiscalização e de informações técnicas.

Existem alguns estudos publicados na literatura nacional que relatam experiências com ações de resgate e realocação de epífitos vasculares, com destaque para os trabalhos com as famílias Bromeliaceae, Cactaceae e Orchidaceae no Rio Grande do Sul (Jasper et al., 2005), de Bromeliaceae e Orchidaceae no estado de São Paulo (Jakovac et al., 2007) e de várias famílias epifíticas no Paraná (Milaneze-Gutierre et al., 2017).

Além do processo de resgate e realocação de epífitos em casos de supressão de florestas (Jasper et al., 2005), também existe a possibilidade de enriquecimento de florestas em processo de restauração (Duarte \& Gandolfi, 2017), incrementando a diversidade pela sua própria presença assim como pela ampliação da probabilidade de atração de fauna, que interage com os epífitos em busca de abrigo, moradia e alimento.

No entanto, a simples ação de implantar epífitos em florestas carece de pesquisas básicas, tais como época de instalação das plantas, forófitos mais adequados e posição nos indivíduos arbóreos. Estas condições tornam-se ainda mais importantes se for considerada a grande diversidade dessas plantas, suas características e a multiplicidade de ambientes que estão em processo de recuperação no Brasil. As especificidades do grupo de epífitos, como a sobrevivência e desenvolvimento relacionados com recursos atmosféricos, nutrientes lixiviados e microambientes proporcionados pelo forófito, reforçam a necessidade de pesquisas para orientar as realocações. Neste sentido, é fundamental compreender as exigências ambientais de cada família epifítica, o que possibilita o desenvolvimento das técnicas mais adequadas. Duarte \& Gandolfi (2017) analisaram a sobrevivência e o desenvolvimento de espécies pertencentes a três famílias (cactáceas, bromeliáceas e orquidáceas), transplantadas para duas áreas com Floresta Estacional Semidecidual no estado de São Paulo, enquanto Jasper et al. (2005) avaliaram a sobrevivência após o resgate de espécies das mesmas famílias botânicas, em zona ecotonar de Floresta Estacional Decidual com Ombrófila Mista no Rio Grande do Sul.

A família Cactaceae ocorre exclusivamente nas Américas, à exceção de Rhipsalis baccifera na África tropical, Madagascar e Sri Lanka (Anderson, 2001). Podem ser terrestres, rupestres ou epifíticas, arbóreas, arbustivas ou escandentes, com caules suculentos e fotossintetizantes (Barthlott \& Hunt, 1993; Anderson, 2001). O armazenamento de água nos caules representa a adaptação quanto à escassez deste recurso, inclusive nas copas das árvores, possibilitando a estas viverem como epífitos, longe do solo, que é fonte direta de água e nutrientes. No entanto, pode-se afirmar que é fundamental investigar a sobrevivência destas plantas à realocação para novos suportes, novos ambientes epifíticos, e as melhores formas para fazê-lo. O transplante de cactáceas é citado em Jasper et al. (2005) para o estado do Rio Grande do Sul. Esses autores relatam sobrevivências distintas conforme as espécies da família, além da 
dificuldade em fazer todas as avaliações em campo. Neste sentido, os estudos em casa de vegetação podem auxiliar na compreensão da capacidade de sobrevivência das espécies, da sua eficiência em emitir brotações e, assim, do potencial para empregá-las em ações de enriquecimento de florestas com epífitos vasculares.

Itaboraí, município do estado do Rio de Janeiro, está inserido em uma unidade fitogeográfica destacadamente rica em epífitos, a Floresta Ombrófila Densa do sudeste brasileiro, região também considerada de elevada diversidade de cactáceas epifíticas tropicais (Taylor \& Zappi, 2004; Calvente et al., 2005). Nesse município, florestas foram restauradas (Prado et al., 2014), e outras, em processo de regeneração natural, foram enriquecidas com epífitos como propulsores da diversidade e das interações ecológicas. A importância dos epífitos e, mais especificamente, das cactáceas nestas regiões, torna as ações de enriquecimento para recomposição dos ecossistemas fundamentais, colaborando com a estruturação do conhecimento básico para ações de resgate e realocação dessas plantas.

Este estudo teve como objetivo responder as seguintes perguntas: (i) A sobrevivência e a formação de ramos e raízes em Rhipsalis lindbergiana K.Schum. e $R$. pachyptera Pfeiff. (Cactaceae) são influenciadas pelo período do ano em que é feita a realocação para floresta em regeneração? (ii) A sobrevivência e a formação de ramos e raízes nestas mesmas espécies estão relacionadas com as dimensões das árvores suporte? (iii) Qual o substrato mais favorável para a sobrevivência e a formação de ramos e raízes destas cactáceas em casa de vegetação? Com estas informações, espera-se contribuir com o desenvolvimento de metodologias para realocação de epífitos vasculares após resgate em caso de supressão de florestas.

\section{Material e métodos}

\section{Caracterização da área}

Os trabalhos foram conduzidos no município de Itaboraí, RJ (2240'10" S e 4247’30"W). As paisagens da região caracterizam-se pela constituição imbricada de unidades litoestratigráficas de caráter sedimentar do Terciário - Formação Macacu, em meio a morros com herança litotípica de elevado grau metamórfico (gnaisses) da Formação São Fidélis de idade Proterozoica (Curcio et al., 2014).

A vegetação da região enquadra-se na unidade fitoecólogica Floresta Ombrófila Densa de Terras Baixas (IBGE, 2012), apresentando-se em diferentes níveis de regeneração. Segundo Gonçalves (2014), o clima é uma transição entre os tipos climáticos $A f$ e $A w$, com temperatura média do mês mais frio superior a $18{ }^{\circ} \mathrm{C}$ e uma breve estação seca, compensada pelos totais elevados de precipitação. Dezembro é o mês mais chuvoso (213 mm de precipitação média), sendo que até fevereiro também ocorrem as maiores temperaturas do ar. Janeiro e fevereiro são os meses mais quentes (maior temperatura máxima média de $29,7^{\circ} \mathrm{C}$ ) e com maior incidência de radiação solar.

O trimestre junho-agosto reúne os meses com menor precipitação, sendo que junho (47 mm de precipitação média) e julho apresentam dias mais curtos e menores temperaturas (mínima média de $14,3{ }^{\circ} \mathrm{C}$ ). A temperatura média anual estimada para a área é de $21,4^{\circ} \mathrm{C}$ e o total médio anual de precipitação pluviométrica é de

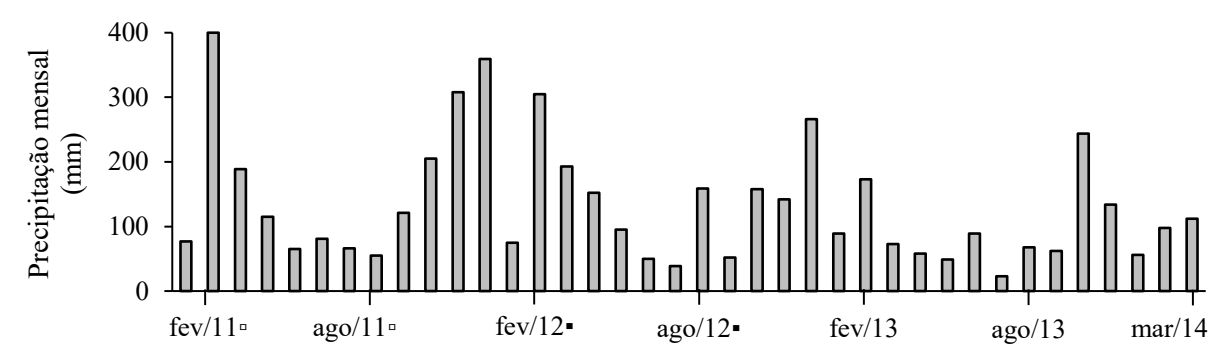

Figura 1. Precipitação média mensal na região de Itaboraí, RJ, com sinalização dos meses de instalação de Rhipsalis lindbergiana ( ) e $R$. pachyptera (•), experimento 2. (Fonte: Ana, 2018).

Figure 1. Average monthly rainfall in Itaboraí region, RJ, with indication of the months of installation of Rhipsalis lindbergiana () and R. pachyptera (•), experiment 2. (Source: Ana, 2018). 
$1.463 \mathrm{~mm}$. Os valores de precipitação mensal do período de desenvolvimento dos trabalhos (2011 a 2014) podem ser observados na Figura 1.

\section{Experimentos}

Foram instalados dois experimentos com Rhipsalis lindbergiana e Rhipsalis pachyptera (Figura 2). Rhipsalis pachyptera possui cladódios aplanados, articulados, pendentes, ramificados e esverdeados, com formato oval a elíptico. Os artículos possuem margens crenadas, e crenas arredondadas. A venação dos artículos é evidente. A ramificação dos artículos é apical ou lateral. As flores são laterais, brancas, e apresentam-se solitárias até em quatro unidades por aréola. Os frutos são globosos, alvos a avermelhados. Rhipsalis lindbergiana possui cladódios cilíndricos, pendentes, verdes, que podem formar agrupamentos densos e alcançar $4 \mathrm{~m}$ de comprimento. As aréolas possuem pequenas escamas triangulares e pelos curtos e brancos, ambos caducos. A ramificação é subterminal. As flores são laterais, solitárias e róseas. Os frutos são globosos e variam de alvos até rosa choque (Anderson, 2001; Zappi et al, 2007).

No experimento 1 foi avaliada a sobrevivência e o desenvolvimento de $R$. lindbergiana e $R$. pachyptera em casa de vegetação (Figura 3), com a utilização de fragmentos dos cladódios mantidos em bandejas sobre diferentes substratos, iniciado em janeiro de 2012 e finalizado em maio de 2012. Os fragmentos dos cladódios foram obtidos através do seccionamento de indivíduos coletados de populações existentes nas
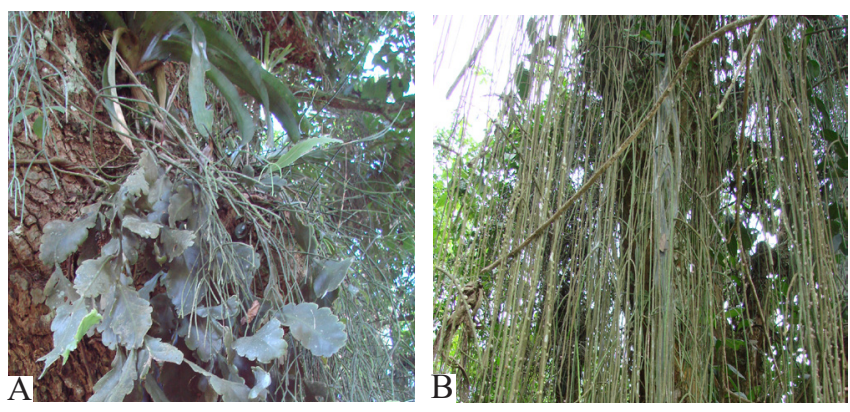

Figura 2. Aspecto geral de a) Rhipsalis pachyptera e b) R.lindbergiana em ambiente natural, Itaboraí, RJ. (Fotos: Annete Bonnet).

Figure 2. General aspect of a) Rhipsalis pachyptera and b) $R$. lindbergiana in natural environment, Itaboraí, Rio de Janeiro State, Brazil. (Photos: Annete Bonnet). florestas da área. Os cladódios foram seccionados em fragmentos com cerca de $20 \mathrm{~cm}$ de comprimento no caso de $R$. lindbergiana (Figura 3A), variando entre 20 e $35 \mathrm{~cm}$ no caso de $R$. pachyptera. Para esta espécie, que possui cladódios articulados, foram mantidos dois artículos no processo de fragmentação (Figura 3B).

$\mathrm{O}$ delineamento experimental foi inteiramente casualizado com três tratamentos e 10 repetições. Os tratamentos foram: T1 - areia (100\%); T2 - areia (50\%) e composto orgânico (50\%); T3 - composto orgânico $(100 \%)$. Este delineamento foi utilizado para as duas espécies no experimento 1 . O composto orgânico utilizado foi obtido através da compostagem de resíduos agrícolas e restos de alimentos, confeccionado segundo o método descrito em Resende et al. (2009). As bandejas foram dispostas sobre bancadas, sob tela sombrite de $50 \%$, sendo irrigadas por micro-aspersão, uma vez por semana, por uma hora. Para cada espécie foram preparadas 30 bandejas $(30 \mathrm{~cm} \times 20 \mathrm{~cm} \times 6 \mathrm{~cm})$, sendo 10 com cada substrato. A colocação dos fragmentos nas bandejas foi realizada no mesmo dia da coleta em campo. Em cada bandeja foram colocados três fragmentos, totalizando 30 fragmentos em cada um dos compostos e 90 fragmentos avaliados por espécie.

Com o objetivo de uniformizar o tipo de substrato para instalação dos epífitos no experimento 2 , foi selecionado fragmento de floresta em regeneração, com ampla expressão de Moquiniastrum polymorphum (Less.) G.
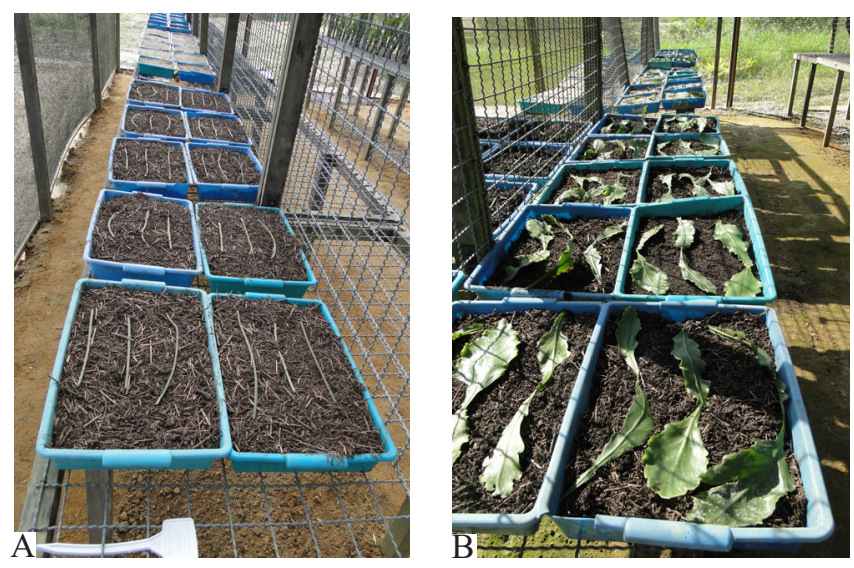

Figura 3. Experimento 1, instalado em casa de vegetação em bandejas com diferentes substratos, Itaboraí, RJ: a) Rhipsalis lindbergiana; b) R. pachyptera. (Fotos: Annete Bonnet).

Figure 3. Experiment 1 carried out in a greenhouse in trays with different substrates in Itaboraí, Rio de Janeiro State, Brazil: a) Rhipsalis lindbergiana; b) R. pachyptera. (Photos: Annete Bonnet). 

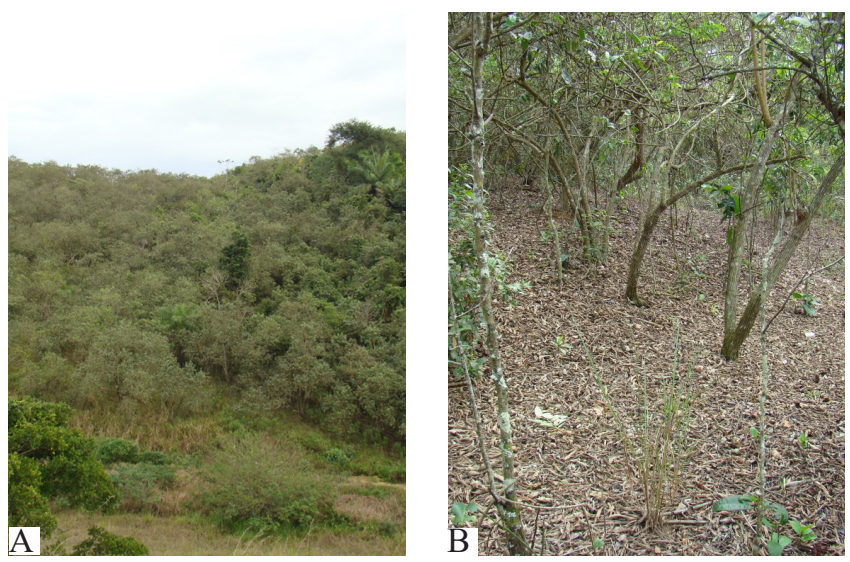

Figura 4. Aspecto externo (a) e interno (b) do fragmento florestal em regeneração com predomínio de Moquiniastrum polymorphum, onde foi instalado o experimento 2, em Itaboraí, RJ. (Fotos: Annete Bonnet).

Figure 4. Exterior (a) and interior (b) aspect of the regenerating forest fragment with predominance of Moquiniastrum polymorphum, where experiment 2 was installed, Itaboraí, Rio de Janeiro State, Brazil. (Photos: Annete Bonnet).

Sancho(Asteraceae), o cambará, situado sobre Latossolos Amarelos Distrocoesos típicos relevo ondulado (15\% de declive), desenvolvidos na Formação Macacu (Bonnet et al., 2014). A área (Figura 4) encontra-se voltada para leste, em altimetrias próximas de $30 \mathrm{~m}$ s.n.m.

A implantação de $R$. lindbergiana e $R$. pachyptera foi realizada em anos e estações climáticas distintas. $\mathrm{O}$ delineamento experimental para as duas espécies foi inteiramente casualizado com dois tratamentos; os tratamentos foram: T1 - implantação em época de chuvas; T2 - implantação em época de seca. A primeira espécie foi instalada em dois lotes: fevereiro (estação de chuvas) e agosto (estação de seca) de 2011. A segunda espécie foi implantada em fevereiro e agosto de 2012, constituindo assim os dois lotes. Cada lote foi composto por 30 fragmentos de cladódios, amarrados individualmente a 30 árvores de $M$. polymorphum (Figura 5), totalizando 60 fragmentos de cada espécie por experimento e 120 fragmentos de cactáceas fixadas ao mesmo grupo de 30 árvores suporte. Os dois lotes de cada espécie foram acompanhados para verificar diferenças na sobrevivência e crescimento dos fragmentos, em função das condições climáticas predominantes. Os fragmentos foram preparados pela secção de indivíduos adultos coletados de populações existentes nos fragmentos florestais da região. Foram
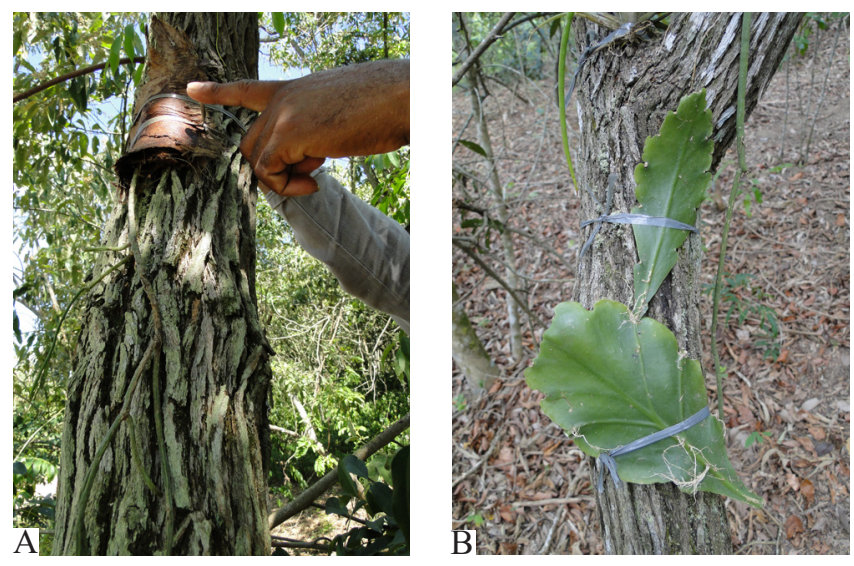

Figura 5. Fragmentos de cladódios de a) Rhipsalis lindbergiana e b) $R$. pachyptera fixados nas árvores com fita plástica e bainhas de folhas de coqueiro, Itaboraí, RJ.

(Fotos: Annete Bonnet).

Figure 5. Cladoses fragments of a) Rhipsalis lindbergiana and b) $R$. pachyptera (b) fixed on trees with plastic tape and sheaths of coconut leaves, Itaboraí, Rio de Janeiro, State, Brazil. (Photos: Annete Bonnet).

seccionados fragmentos de $R$. lindbergiana com cerca de $60 \mathrm{~cm}$ de comprimento, geralmente com cladódios bifurcados (Figura 5A). No caso de R. pachyptera, foram seccionados fragmentos com aproximadamente $30 \mathrm{~cm}$ de comprimento e com dois artículos, a exemplo do material preparado para o experimento 1 (Figura 5B). Os fragmentos foram fixados separadamente nas árvores suporte em alturas de aproximadamente 1,5 $\mathrm{m}$ e 2,0 $\mathrm{m}$ a partir da superfície do solo, usando-se fita plástica e, no caso de $R$. lindbergiana, complementadas com bainhas de folhas de coqueiro disponíveis na área, para envolver o cladódio e proteger a planta da pressão da fita plástica. A fixação dos fragmentos nas árvores foi realizada em, no máximo, 24 h após a coleta em campo.

As árvores utilizadas como suporte encontravam-se distribuídas em área menor que um hectare e cada uma delas foi identificada com placa de metal numerada. De cada árvore suporte foram registrados altura total, diâmetro a 1,30 m do solo (DAP) e diâmetro no local de fixação dos fragmentos de cladódios (Figura 5), sendo estas variáveis utilizadas para análise da relação com os dados de sobrevivência e crescimento das cactáceas.

\section{Avaliação da sobrevivência e do desenvolvimento}

O experimento 1 foi avaliado por quatro meses, com realização de três leituras (fevereiro, março e maio 
de 2012). Registraram-se, como variáveis resposta, a sobrevivência e presença de novas raízes e novos ramos ao longo dos fragmentos de cladódios instalados nas bandejas mantidas em casa de vegetação. Na terceira leitura do experimento também foram registrados o número de ramos e o comprimento do maior ramo em cada fragmento de cladódio. As variáveis preditoras consistem nos três distintos substratos das bandejas (areia, misto e composto) e os meses de leitura.

Para avaliar a sobrevivência e anotar o desenvolvimento dos fragmentos do experimento 2 , foram feitas avaliações semestrais, até completar o período máximo de três anos para $R$. lindbergiana (início em fevereiro de 2011) e dois anos para $R$. pachyptera (início em fevereiro de 2012), tendo sido realizada a leitura final para ambas em março de 2014. Como variáveis resposta foram registradas: sobrevivência, indivíduos com novos ramos (emitidos desde a implantação do experimento na floresta), com novas raízes, além do número de ramos por fragmento e tamanho da planta (comprimento do maior ramo). $\mathrm{Na}$ instalação dos experimentos foram registrados os comprimentos totais de $R$. lindbergiana (tamanho do maior artículo a partir da base), repetindo-se anualmente as leituras. Para $R$. pachyptera foi contabilizado, semestralmente, o número de novos artículos formados (ramos) e, na última leitura do experimento, o comprimento do ramo mais longo. A mensuração das variáveis comprimento dos ramos e tamanho da planta foi realizada com o auxílio de fita métrica nos dois experimentos. Foram consideradas variáveis preditoras as estações de chuva (fevereiro) e de seca (agosto) e os meses. Com os dados coletados no experimento 2, as variáveis sobrevivência e porcentagem de indivíduos com raízes e com ramos, ao longo dos meses (variáveis resposta) foram analisadas em função das dimensões das árvores suporte (altura total, DAP e diâmetro no local de fixação dos fragmentos - variáveis preditoras).

Foram considerados vivos, para ambos os experimentos, os fragmentos de cladódios com tecidos verdes e com capacidade de se desenvolver, e mortos aqueles formados por tecidos secos e sem capacidade de crescer. Ramos e raízes novos foram facilmente diferenciados por sua aparência, não sendo necessárias marcações para diferenciação.

Análise dos dados

No experimento 1, as diferenças na sobrevivência, formação de ramos e de raízes, número e comprimento dos ramos formados nos fragmentos das duas espécies de cactáceas entre os três substratos das bandejas foram examinadas por modelos lineares generalizados (McCullagh \& Nelder, 1989), tomando os efeitos principais de modo inteiramente aleatório e interações fatoriais de substrato e tempo. Os efeitos significativos foram decompostos por contrastes ortogonais, previamente definidos: contraste 1 - Misto versus areia e composto e contraste 2 - areia versus composto (Stell $\&$ Torrie, 1980).

No experimento 2, utilizou-se a distribuição binomial e função de ligação logit para verificar se foi distinta a sobrevivência das plantas implantadas nos dois lotes (estações de chuvas e de seca). O mesmo teste foi empregado para verificar diferenças quanto à formação de raízes e de ramos. Para analisar o número de ramos formados, utilizou-se a distribuição de Poisson e função de ligação logarítmica. O comprimento dos ramos formados foi analisado seguindo a distribuição normal e função de ligação identidade (McCullagh \& Nelder, 1989). A verificação da significância dos efeitos para os modelos testados foi feita através da estatística deviance, assumindo-se independências das observações. A validação do ajuste do modelo foi verificada pelo gráfico meionormal (half-normal plot) com envelope simulado (Collet, 1991). As relações entre a sobrevivência e formação de raízes e ramos com DAP e altura da árvore e DAP do ramo onde a planta foi fixada foram testadas através do coeficiente de correlação ponto-bisserial, complementado pelo teste de significância.

\section{Resultados}

De modo geral, tanto as cactáceas mantidas em casa de vegetação, quanto aquelas realocadas para floresta em regeneração apresentaram sobrevivência da maioria dos fragmentos, independente de substrato ou períodos de maior ou menor chuva.

\section{Sobrevivência e desenvolvimento em casa de vegetação}

A sobrevivência de Rhipsalis lindbergiana e $R$. pachyptera (Tabela 1 ), ao final do experimento, foi alta (90 a 87\%, respectivamente), independente do substrato onde cresciam. Observou-se formação de raízes e ramos nas duas espécies, em 30 dias após o início do experimento, nos três substratos empregados. 
A sobrevivência e formação de raízes nos cladódios de $R$. lindbergiana não foram influenciadas pelo substrato (Tabela 1). A formação de ramos foi significativamente maior nas bandejas com substrato misto em um mês de experimentação, e nas bandejas com composto após quatro meses. $\mathrm{O}$ número médio de ramos formados e o tamanho médio dos ramos também foram maiores nas bandejas com composto (Tabela 1).

Em geral, as raízes, independente do substrato da bandeja, cresceram na porção dos cladódios em contato com o substrato, e em uma das extremidades do fragmento de $R$. lindbergiana (Figura 6A). Os ramos, por sua vez, apresentaram brotação subterminal (Figura 6B).

Tabela 1. Sobrevivência, indivíduos com raízes e ramos, comprimento e número médio de ramos de Rhipsalis lindbergiana em diferentes substratos, Itaboraí, RJ.

Table 1. Survival, individuals with roots and branches, length and average number of branches of Rhipsalis lindbergiana in different substrates, Itaboraí, Rio de Janeiro State, Brazil.

\begin{tabular}{|c|c|c|c|c|c|}
\hline \multirow{3}{*}{$\begin{array}{c}\text { Meses } \\
\text { (M) }\end{array}$} & \multicolumn{3}{|c|}{ Substrato (S) } & \multirow{2}{*}{\multicolumn{2}{|c|}{$\begin{array}{c}p \text { valor } \\
\text { Contraste ortogonais }\end{array}$}} \\
\hline & \multirow{2}{*}{$\begin{array}{l}\text { Areia } \\
\text { (A) }\end{array}$} & \multirow{2}{*}{$\begin{array}{l}\text { Misto } \\
\text { (TO) }\end{array}$} & \multirow{2}{*}{$\begin{array}{c}\text { Composto } \\
\text { (C) }\end{array}$} & & \\
\hline & & & & TO vs A, C & A vs C \\
\hline \multicolumn{6}{|c|}{ Sobrevivência (\%) } \\
\hline implantação & 100 & 100 & 100 & 1,0000 & 1,0000 \\
\hline 1 & 100 & 100 & 100 & 1,0000 & 1,0000 \\
\hline 2 & 100 & 97 & 100 & 0,1363 & 1,0000 \\
\hline 4 & 90 & 97 & 90 & 0,2339 & 1,0000 \\
\hline \multicolumn{6}{|c|}{ Raízes (\%) } \\
\hline implantação & 0 & 0 & 0 & 1,0000 & 1,0000 \\
\hline 1 & 83 & 87 & 90 & 0,9622 & 0,4454 \\
\hline 2 & 90 & 90 & 90 & 1,0000 & 1,0000 \\
\hline 4 & 87 & 90 & 90 & 0,8226 & 0,6871 \\
\hline \multicolumn{6}{|c|}{$\operatorname{Ramos}(\%)$} \\
\hline implantação & 0 & 0 & 0 & 1,0000 & 1,0000 \\
\hline 1 & 27 & 63 & 20 & 0,0002 & 0,5410 \\
\hline 2 & 53 & 90 & 83 & $\mathbf{0 , 0 3 3 3}$ & 0,0112 \\
\hline 4 & 57 & 87 & 90 & 0,3101 & 0,0027 \\
\hline \multicolumn{6}{|c|}{$\mathrm{N}^{0}$ médio de ramos/planta } \\
\hline 4 & 1,4 & 2,1 & 2,5 & 0,0637 & $<0,0001$ \\
\hline \multicolumn{6}{|c|}{ Comprimento médio de ramos $(\mathrm{cm})$} \\
\hline 4 & 11,1 & 27,5 & 32,7 & 0,1010 & $<\mathbf{0 , 0 0 0 1}$ \\
\hline
\end{tabular}

Onde: valores $p$ em negrito $=$ significativo a $1 \%$ pelo teste qui-quadrado $\left(\mathrm{X}^{2}\right)$.

Semelhante a $R$. lindbergiana, a sobrevivência e formação de raízes nos cladódios de $R$. pachyptera não foram influenciadas, ao longo dos quatro meses de observação, pelo substrato disposto nas bandejas (Tabela 2). No entanto, as porcentagens de formação, os números médios e os tamanhos dos ramos foram distintos, conforme os substratos presentes nas bandejas.

Aos dois meses, a porcentagem de indivíduos ramificados foi distinta entre os três substratos e, ao final do experimento, o maior número de ramos foi registrado na bandeja do composto. Também nas bandejas unicamente com composto foram apontados os maiores comprimentos dos ramos. Destaca-se que o número médio de ramos, por fragmento de cladódio de $R$. pachyptera, foi maior nas bandejas com substrato misto, mas em valor semelhante ao obtido nas bandejas com composto.

As raízes cresceram, na grande maioria, em uma das extremidades do fragmento do cladódio, esbranquiçadas e em grande quantidade (Figura 7A), embora algumas tenham surgido também ao longo dos artículos, sempre na superfície voltada para o substrato. 

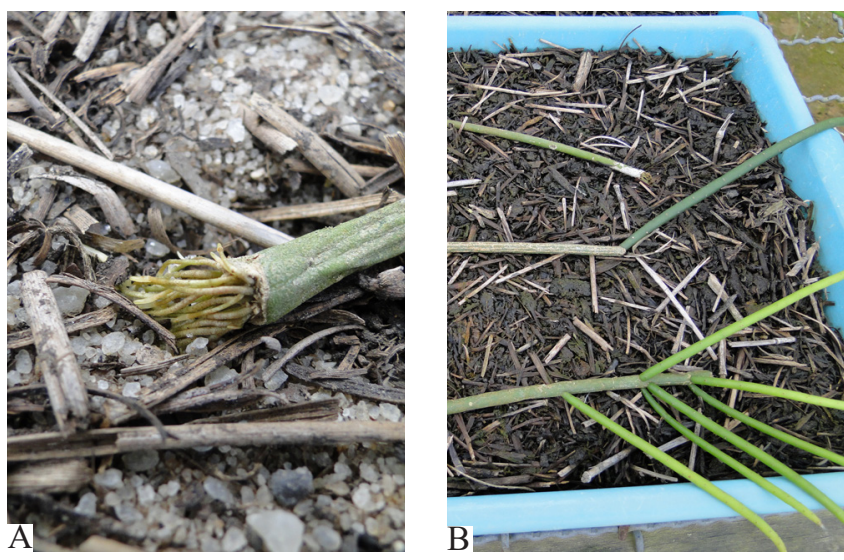

Figura 6. Crescimento de a) raízes e de b) ramos de Rhipsalis lindbergiana em casa de vegetação, Itaboraí, RJ. (Fotos: Annete Bonnet).

Figure 6. Growth of a) roots and b) branches of Rhipsalis lindbergiana in a greenhouse, Itaboraí, Rio de Janeiro State. (Photos: Annete Bonnet).

Os ramos foram formados em várias posições (Figura 7 B), como nas extremidades livre do artículo mais jovem, na união entre os artículos e nas margens de ambos.

\section{Sobrevivência e desenvolvimento em floresta em regeneração}

No lote instalado em agosto de 2011, na estação seca, houve maior sobrevivência de $R$. lindbergiana do que no lote instalado em fevereiro de 2011, na estação das chuvas, resultado registrado desde os primeiros 12 meses em campo (Tabela 3). A mortalidade dos fragmentos instalados no período de seca foi registrada nos seis primeiros meses, restando $97 \%$ das plantas após 30 meses de experimentação. Os fragmentos instalados na estação de chuvas morreram, principalmente, nos 12 primeiros meses de experimentação, resultando em apenas 53\% das plantas vivas após três anos de observações.

O mesmo padrão foi registrado para a formação de raízes, com maior porcentagem de fragmentos que formaram raízes no lote da estação de seca a partir de 12 meses de experimentação (Tabela 3). Destacase que aos 24 meses todos os fragmentos vivos de ambos os lotes apresentavam raízes. As raízes e os ramos foram formados ao longo de toda a extensão dos cladódios, sendo as raízes muito visíveis devido à sua coloração esbranquiçada.

As diferenças quanto à formação de ramos e o comprimento das plantas entre os dois lotes, das estações de seca e de chuvas, também se mostraram significativas
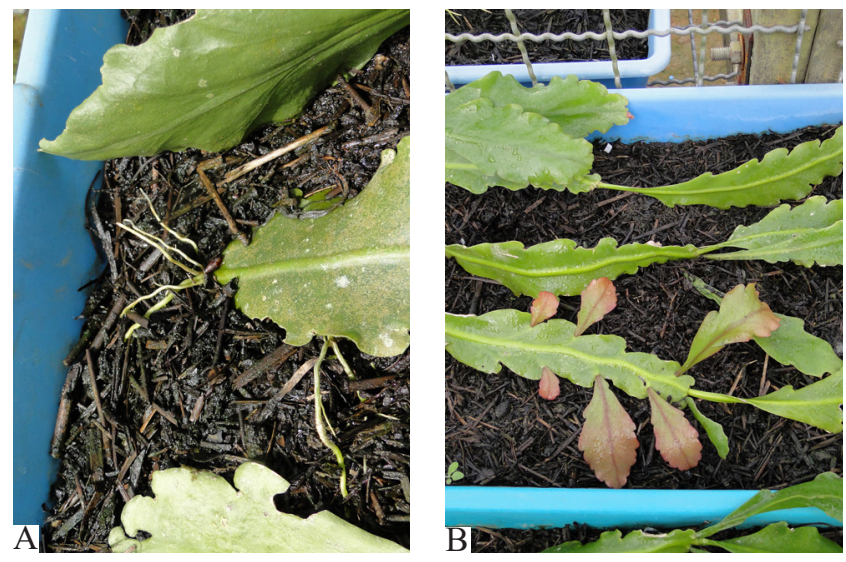

Figura 7. Crescimento de a) raízes e b) ramos de Rhipsalis pachyptera em casa de vegetação, Itaboraí, RJ.(Fotos: Annete Bonnet).

Figure 7. Growth of a) roots and b) branches of Rhipsalis pachyptera in a greenhouse, Itaboraí, Rio de Janeiro State. (Photos: Annete Bonnet).

aos 12 meses de implantação (Tabela 4). Destaca-se que, em seis meses após a realocação, a grande maioria dos fragmentos ( $90 \%$ no lote de seca e $63 \%$ no lote de chuva) formou novos ramos. Em 30 meses, todos os fragmentos de ambos os lotes, apresentavam novos ramos. Estes cresceram em várias posições ao longo dos cladódios, inclusive com formação de novos ramos a partir dos recém-formados.

Do mesmo modo, aos 24 meses, o número médio de ramos formados por fragmento no lote de seca $(19,4 \mathrm{ramos} /$ planta $)$ foi significativamente maior do que no lote de chuva ( $8,1 \mathrm{ramos} / \mathrm{planta})$. Aos 30 meses, registrou-se a média de 22,8 ramos por planta no lote implantado na estação de seca (Tabela 4).

O teste das relações entre sobrevivência e desenvolvimento com as características das árvores onde $R$. lindbergiana foi fixada (coeficiente de correlação ponto-bisserial e teste de significância) revelou significância entre a altura das árvores com a sobrevivência $\left(\mathrm{r}_{\mathrm{b}}=0,6448 ; p\right.$ valor 0,02497$)$, com a formação de raízes $\left(\mathrm{r}_{\mathrm{b}}=0,6413 ; p\right.$ valor 0,018552$) \mathrm{e}$ formação de ramos $\left(\mathrm{r}_{\mathrm{b}}=0,6315\right.$; $\mathrm{p}$ valor 0,021585$)$.

A sobrevivência dos fragmentos de cladódio de $R$. pachyptera não variou significativamente, independente do período de implantação em campo (Tabela 5). No entanto, só houve mortalidade dos fragmentos de cladódio do lote de seca (instalado em agosto de 2012) até seis meses (17\%) após a realocação, resultando em $83 \%$ dos indivíduos vivos até aos 18 meses. O 
Técnica de realocação de Rhipsalis (Cactaceae) em florestas regenerantes, em Itaboraí - RJ: sobrevivência e desenvolvimento 9 de 16

Tabela 2. Sobrevivência, indivíduos com raízes e ramos, comprimento médio e número de ramos de $R$. pachyptera em diferentes substratos, Itaboraí, RJ.

Table 2. Survival, individuals with roots and branches, average length and number of branches of $R$. pachyptera in different substrates, Itaboraí, Rio de Janeiro State, Brazil.

\begin{tabular}{|c|c|c|c|c|c|}
\hline \multirow{3}{*}{$\begin{array}{l}\text { Meses } \\
(\mathrm{M})\end{array}$} & \multicolumn{3}{|c|}{ Substrato (S) } & \multirow{2}{*}{\multicolumn{2}{|c|}{$\begin{array}{c}p \text { valor } \\
\text { Contraste ortogonais }\end{array}$}} \\
\hline & \multirow{2}{*}{$\begin{array}{c}\text { Areia } \\
\text { (A) }\end{array}$} & \multirow{2}{*}{$\begin{array}{l}\text { Misto } \\
\text { (TO) }\end{array}$} & \multirow{2}{*}{$\begin{array}{c}\text { Composto } \\
\text { (C) }\end{array}$} & & \\
\hline & & & & TO vs A, C & A vs C \\
\hline \multicolumn{6}{|c|}{ Sobrevivência (\%) } \\
\hline implantação & 100 & 100 & 100 & 1,0000 & 1,0000 \\
\hline 1 & 100 & 100 & 100 & 1,0000 & 1,0000 \\
\hline 2 & 100 & 93 & 100 & 0,0342 & 1,0000 \\
\hline 4 & 90 & 87 & 97 & 0,2496 & 0,2904 \\
\hline \multicolumn{6}{|c|}{ Raízes (\%) } \\
\hline implantação & 0 & 0 & 0 & 1,0000 & 1,0000 \\
\hline 1 & 87 & 83 & 97 & 0,1702 & 0,1482 \\
\hline 2 & 97 & 87 & 97 & 0,0838 & 1,0000 \\
\hline 4 & 90 & 87 & 97 & 0,2496 & 0,2904 \\
\hline \multicolumn{6}{|c|}{ Ramos (\%) } \\
\hline implantação & 0 & 0 & 0 & 1,0000 & 1,0000 \\
\hline 1 & 7 & 3 & 20 & 0,1635 & 0,1213 \\
\hline 2 & 37 & 30 & 80 & 0,0083 & 0,0005 \\
\hline 4 & 43 & 70 & 90 & 0,8262 & $<0,0001$ \\
\hline \multicolumn{6}{|c|}{$\mathrm{N}^{0}$ médio de ramos/planta } \\
\hline 4 & 1,1 & 3 & 2,7 & 0,0004 & $<0,0001$ \\
\hline \multicolumn{6}{|c|}{ Comprimento médio de ramos $(\mathrm{cm})$} \\
\hline 4 & 8,0 & 11,0 & 17,2 & 0,0681 & $<0,0001$ \\
\hline Fonte de Variação & Deviance & Qui-Quadrado & $\mathrm{p}$ valor & & \\
\hline Substrato (S) & 119,89 & 24,82 & $<0,0001$ & & \\
\hline
\end{tabular}

Onde: valores $p$ em negrito = significativo a $1 \%$ pelo teste qui-quadrado $\left(\mathrm{X}^{2}\right)$.

Tabela 3. Registros semestrais da sobrevivência e da formação de raízes em Rhipsalis lindbergiana, a partir da realocação para a floresta em regeneração, Itaboraí, RJ.

Table 3. Semiannual records of survival and root formation in Rhipsalis lindbergiana, from relocation to the regenerating forest, Itaboraí, Rio de Janeiro State, Brazil.

\begin{tabular}{|c|c|c|c|c|c|c|}
\hline \multirow{2}{*}{ Meses } & \multicolumn{2}{|c|}{ Sobrevivência (\%) } & \multirow[t]{2}{*}{$p$ valor } & \multicolumn{2}{|c|}{ Formação de raízes (\%) } & \multirow[t]{2}{*}{$p$ valor } \\
\hline & chuva & seca & & chuva & seca & \\
\hline implantação & 100 & 100 & 1,0000 & 0 & 0 & 1,0000 \\
\hline 6 & 97 & 97 & 1,0000 & 77 & 80 & 0,7539 \\
\hline 12 & 57 & 97 & $<0,0001$ & 53 & 93 & $<0,0001$ \\
\hline 18 & 57 & 97 & $<0,0001$ & 53 & 97 & $<0,0001$ \\
\hline 24 & 57 & 97 & $<\mathbf{0 , 0 0 0 1}$ & 57 & 97 & $<0,0001$ \\
\hline 30 & 53 & 97 & $<0,0001$ & 53 & 97 & $<0,0001$ \\
\hline 36 & 53 & - & - & 53 & - & - \\
\hline
\end{tabular}

Onde: valores $p$ em negrito $=$ significativo a $1 \%$ pelo teste qui-quadrado $\left(\mathrm{X}^{2}\right)$. 
Tabela 4. Registros semestrais do número de $R$. lindbergiana que formaram ramos, do número médio de ramos formados e do comprimento médio das plantas, a partir da realocação para a floresta em regeneração, Itaboraí, RJ.

Table 4. Semiannual records of the number of cladode fragments of R. lindbergiana that formed branches, the average number of branches formed and the average length of plants, from the relocation to the regenerating forest, Itaboraí, Rio de Janeiro State, Brazil.

\begin{tabular}{|c|c|c|c|c|c|c|c|c|c|}
\hline \multirow{2}{*}{ Meses } & \multicolumn{2}{|c|}{$\begin{array}{c}\text { Formação de } \\
\operatorname{ramos}(\%)\end{array}$} & \multirow[t]{2}{*}{$p$ valor } & \multicolumn{2}{|c|}{$\begin{array}{c}\mathrm{N}^{0} \text { médio ramos } \\
\text { planta }^{-1}\end{array}$} & \multirow[t]{2}{*}{$p$ valor } & \multicolumn{2}{|c|}{$\begin{array}{c}\text { Compr. médio } \\
\text { plantas }(\mathrm{cm})\end{array}$} & \multirow[t]{2}{*}{$p$ valor } \\
\hline & chuva & seca & & chuva & seca & & chuva & seca & \\
\hline implantação & 0 & 0 & - & 0 & 0 & - & 86,2 & 83,3 & - \\
\hline 6 & 63 & 90 & 0,0124 & - & - & - & - & - & - \\
\hline 12 & 53 & 90 & 0,0005 & - & - & - & 76,9 & 107,9 & 0,0012 \\
\hline 18 & 53 & 93 & $<0,0001$ & - & 17,0 & - & - & 130,8 & - \\
\hline 24 & 57 & 93 & 0,0006 & 8,1 & 19,4 & $<0,0001$ & 132,2 & 135,6 & 0,6225 \\
\hline 30 & 53 & 97 & $<0,0001$ & 10,4 & 22,8 & $<0,0001$ & - & 172,9 & - \\
\hline 36 & 53 & - & - & 14,4 & - & - & 176,9 & - & - \\
\hline
\end{tabular}

Onde: valores $p$ em negrito = significativo a $1 \%$ pelo teste qui-quadrado $\left(\mathrm{X}^{2}\right)$.

lote na estação de chuvas (fevereiro de 2012) também apresentou mortalidade maior nos primeiros seis meses (27\%), mas alguns fragmentos ainda morreram até a conclusão do experimento, finalizando com apenas $67 \%$ das cactáceas vivas.

Do mesmo modo, não houve diferenças estatisticamente significativas entre os lotes quanto à formação de raízes (Tabela 5). Todos os fragmentos de cladódios que sobreviveram à realocação para a floresta produziram raízes.

A porcentagem de fragmentos que formaram ramos foi distinta apenas no registro aos seis meses de realocação, quando o lote implantado na estação de seca apresentou maior formação de ramos ( $77 \%$ dos fragmentos) do que o lote de chuva (23\%) (Tabela 6). Mas, ao longo do tempo, as diferenças entre os lotes desapareceram. De modo geral, para ambos os lotes, os ramos surgiram na união dos dois artículos e nas extremidades, principalmente na margem do artículo mais jovem. As raízes, por sua vez, brotaram da extremidade basal dos artículos, assim como na posição da nervura central, ao longo dos mesmos, em contato com o ritidoma das árvores.

O número médio de ramos produzidos após realocação dos fragmentos de cladódios de $R$. pachyptera foi distinto entre os dois lotes (6, 12 e 18 meses). Em todas as observações, o lote implantado em época de seca apresentou maior número de ramos do que os fragmentos do lote de chuva (Tabela 6), apresentando 5,1 ramos planta ${ }^{-1}$ aos 18 meses.

O comprimento dos ramos de $R$. pachyptera, registrado apenas na última leitura, apresentou média de $51,5 \mathrm{~cm}(\mathrm{CV}=45,4 \%)$ para os indivíduos realocados a 24 meses, enquanto para os indivíduos do lote de seca foi verificada média de 46,6 $\mathrm{cm}(\mathrm{CV}=33,5 \%)$ aos 18 meses de experimentação. Quando testadas as relações entre a sobrevivência e formação de raízes e ramos de $R$. pachyptera com as características das árvores, nenhuma se mostrou significativa (Tabela 5).

Tabela 5. Registros semestrais da sobrevivência e da formação de raízes em Rhipsalis pachyptera, a partir da realocação para a floresta em regeneração, Itaboraí, RJ.

Table 5. Semiannual records of survival and roots formation in Rhipsalis pachyptera from relocation to a regenerating forest, Itaboraí, Rio de Janeiro State, Brazil.

\begin{tabular}{|c|c|c|c|c|c|c|}
\hline \multirow{2}{*}{ Meses } & \multicolumn{2}{|c|}{ Sobrevivência (\%) } & \multirow[t]{2}{*}{$p$ valor } & \multicolumn{2}{|c|}{ Formação de raízes (\%) } & \multirow[t]{2}{*}{$p$ valor } \\
\hline & chuva & seca & & chuva & seca & \\
\hline implantação & 100 & 100 & - & 0 & 0 & - \\
\hline 6 & 73 & 83 & 0,3454 & 70 & 73 & 0,7745 \\
\hline 12 & 73 & 83 & 0,3454 & 73 & 80 & 0,5410 \\
\hline 18 & 70 & 83 & 0,2196 & 70 & 83 & 0,2196 \\
\hline 24 & 67 & - & - & 67 & - & - \\
\hline
\end{tabular}



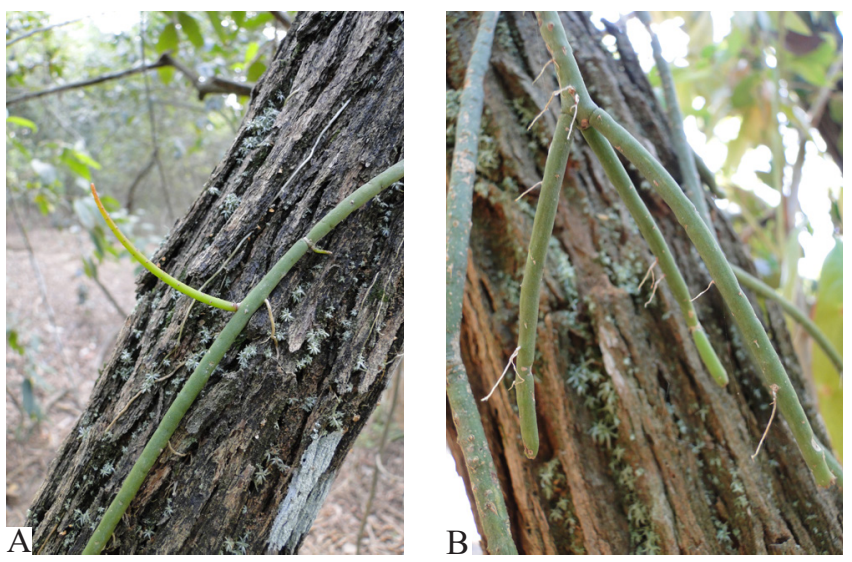

Figura 8. Crescimento de a) ramos e b) raízes de Rhipsalis lindbergiana após 30 dias de realocação para floresta em regeneração, Itaboraí, RJ. (Fotos: Annete Bonnet).

Figure 8. Growth of a) branches and b) roots of Rhipsalis lindbergiana 30 days after relocation to regenerating forest, Itaboraí, Rio de Janeiro State, Brazil. (Photos: Annete Bonnet).
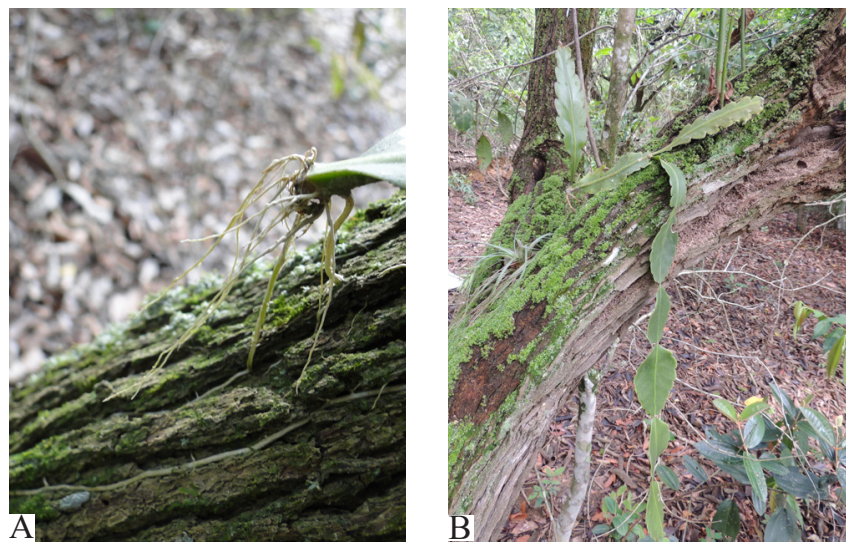

Figura 9. Crescimento de a) raízes após 6 meses e b) ramos após 24 meses, de Rhipsalis pachyptera em floresta em regeneração, Itaboraí, RJ. (Fotos: Annete Bonnet).

Figure 9. Growth of a) roots after 6 months and b) branches after 24 months of Rhipsalis pachyptera in a regenerating forest, Itaboraí, Rio de Janeiro State, Brazil. (Photos: Annete Bonnet).

Tabela 6. Registros semestrais do número de Rhipsalis pachyptera que formaram ramos e do número médio de ramos formados, a partir da realocação para a floresta em regeneração, Itaboraí, RJ.

Table 6. Semi-annual records of the number of Rhipsalis pachyptera fragments that formed branches and the average number of branches formed, from the relocation to a regenerating forest, Itaboraí, Rio de Janeiro State, Brazil.

\begin{tabular}{|c|c|c|c|c|c|c|}
\hline \multirow[t]{2}{*}{ Meses } & \multicolumn{2}{|c|}{ Formação de ramos (\%) } & \multirow[t]{2}{*}{$p$ valor } & \multicolumn{2}{|c|}{$\begin{array}{c}\mathrm{N}^{0} \text { médio } \\
\text { ramos planta }\end{array}$} & \multirow[t]{2}{*}{$p$ valor } \\
\hline & chuva & seca & & chuva & seca & \\
\hline implantação & 0 & 0 & - & 0 & 0 & - \\
\hline 6 & 23 & 77 & $<0,0001$ & 1,1 & 1,9 & $<0,0001$ \\
\hline 12 & 60 & 77 & 0,1634 & 2 & 2,9 & 0,0028 \\
\hline 18 & 60 & 77 & 0,1634 & 2,9 & 5,1 & $<0,0001$ \\
\hline 24 & 67 & - & - & 4,1 & - & - \\
\hline
\end{tabular}

Onde: valores $p$ em negrito $=$ significativo a $1 \%$ pelo teste qui-quadrado $\left(\mathrm{X}^{2}\right)$.

\section{Discussão}

Os resultados da casa de vegetação (Tabelas 1 e 2) ratificaram parcialmente os resultados obtidos em campo em relação à sobrevivência dos fragmentos de cladódios e à formação de raízes (Tabelas 3 a 6). De modo geral, estas variáveis se mostraram independentes da umidade disponibilizada pelos substratos das bandejas e dos períodos com maior ou com menor precipitação para as duas espécies. A sobrevivência e formação de raízes se mostraram significativamente relacionadas com as do ano (estação seca) apenas para Rhipsalis lindbergiana.

Por outro lado, a porcentagem de fragmentos com formação de ramos, bem como o número e o comprimento dos mesmos foram positivamente influenciados, nas duas espécies, pelo substrato das bandejas que continham matéria orgânica (Tabelas 1 e 2). Considerando que as bandejas recebiam irrigação igual, pode-se afirmar que a matéria orgânica foi responsável pela manutenção de umidade no substrato, além da disponibilização de nutrientes para as cactáceas, assegurando o registro de respostas positivas no desenvolvimento das duas espécies. A matéria orgânica possui estrutura amorfa e grande quantidade de cargas iônicas, o que possibilita sua relevante capacidade de retenção de água - ela retém 20 vezes seu peso em água (Stevenson, 1994). A matéria orgânica promove boa estrutura do solo, além de servir como fonte de N, P e S para crescimento 
das plantas (Mielniczuk, 2008). Nas bandejas com substrato formado predominantemente por areia, estas prerrogativas não estavam disponíveis.

$\mathrm{Na}$ floresta, as variáveis relacionadas aos ramos formados nos cladódios se mostraram estatisticamente relacionadas com as estações do ano em um número maior de leituras em $R$. lindbergiana do que em $R$. pachyptera (Tabelas 4 e 6). As diferenças entre as respostas das espécies podem estar relacionadas com a morfologia das plantas. Infere-se que as reservas de umidade e nutrientes existentes dentro dos artículos de $R$. pachyptera, em comparação com $R$. lindbergiana, assim como a breve resposta das plantas através da rápida formação de raízes, teriam favorecido o estabelecimento dessa espécie. A existência de artículos relativamente grandes (com cerca de $20 \mathrm{~cm}$ de comprimento por $7 \mathrm{~cm}$ de largura - Figura 7), representaria, por comparação com a outra espécie, maior espaço para armazenamento de água, que serviria para manutenção das suas funções metabólicas básicas, inclusive enquanto a planta não possui raízes ativas. Adicionalmente, aponta-se a possibilidade de parte dos fragmentos de cladódios que morreram (33\% no lote com maior mortalidade - Tabela 5) terem sido amarrados com força excessiva ao tronco, provocando danos à estrutura da planta.

Destaca-se, no entanto, que $R$. pachyptera, em campo, produziu maior número de ramos no lote implantado na estação de seca do que na estação das chuvas (Tabela 6) - este resultado indica que as condições climáticas são importantes para a sobrevivência, formação de raízes ou de ramos (atividades supridas pelas reservas da planta) das cactáceas, mas não logo após a realocação, e sim para o desenvolvimento desses ramos ao longo dos meses que se sucedem. Com o indivíduo estabelecido e raízes em atividade, o suprimento de água do ambiente torna-se então relevante - cactáceas têm a capacidade de absorver água rapidamente assim que há precipitação (Anderson, 2001).

Para os fragmentos de $R$. lindbergiana implantados na floresta em regeneração, as diferenças em sobrevivência e formação de raízes e ramos entre lotes de seca e de chuva foram significativas desde as primeiras leituras (Tabelas 3 e 4). As plantas do lote implantado na estação de seca apresentaram melhores resultados, evidenciado, por exemplo, com a mortalidade aos 30 meses, que foi de apenas 3\% das plantas realocadas no período de seca e de $47 \%$ nas plantas do lote de chuva (Tabela 3 ).
Os resultados obtidos nesse trabalho podem ser resultantes não apenas do efeito do período climático na época da implantação de $R$. lindbergiana e R. pachyptera na floresta em regeneração, mas principalmente da precipitação pluviométrica que sucedeu à implantação (Figura 1). Ou seja, a precipitação foi aumentando ao longo dos meses que seguiram a implantação dos lotes de seca (agosto de 2011 e agosto de 2012), aqui avaliada pelas médias mensais de precipitação (Figura 1), e a sobrevivência destas plantas foi maior do que aquelas instaladas na estação das chuvas (fevereiro de 2011 e de 2012). As plantas do lote de seca sobreviveram ao período inicial e depois puderam se beneficiar dos meses com precipitação crescente, ou seja, maior disponibilidade de umidade no ambiente, o que resultou em maiores taxas de sobrevivência. Avaliações equivalentes, com relocação de epífitos vasculares em estações climáticas distintas, não foram encontradas na literatura, mas os resultados podem ser comparados com os dados obtidos por Nadkarni \& Solano (2002), que transplantaram experimentalmente epífitos entre ambientes com umidades distintas na Costa Rica. Esses autores obtiveram menor desenvolvimento e sobrevivência nas plantas realocadas para as áreas com menor umidade atmosférica, com impacto mais severo nos epífitos transplantados na estação seca do que na estação úmida. Rapp \& Silman (2014) corroboraram essa relação de maior desenvolvimento de epífitos realocados para áreas com maior umidade através de resultados obtidos no Peru, mas com acompanhamento de apenas um ano.

As respostas de $R$. lindbergiana em sobrevivência e desenvolvimento após realocação também devem ser avaliadas considerando a sua reduzida estrutura dos artículos em eixos cilíndricos (Anderson, 2001- Figura 2B), o que possibilita menor capacidade de armazenar água. Para esta espécie, a precipitação que ocorreu após a realocação foi, possivelmente, fundamental para sua sobrevivência, formação de raízes e ramos.

$R$. lindbergiana também apresentou relações significativas entre a altura das árvores que serviram de suporte com a sobrevivência, formação de raízes e de ramos nos indivíduos, atestando que características da floresta foram importantes no sucesso da realocação da espécie. Este resultado provavelmente remete à relação de árvores suporte de maior tamanho com maior diversidade e abundância de epífitos (Bonnet et al., 2010; Marcusso et al., 2019), apesar do teste com o diâmetro 
das árvores não ter se mostrado significativo. De qualquer modo, é possível afirmar que árvores de maior porte sejam mais adequadas como suporte de epífitos realocados, considerando a maior disponibilidade de microclimas com diferentes combinações de umidade e sombreamento, o maior porte para suportar peso elevado quando os indivíduos se desenvolverem e formarem agrupamentos, assim como maior superfície disponível nos galhos para o enraizamento. Neste sentido, Garcia et al. (2016) destacam que forófitos de espécies pioneiras na sucessão da vegetação devem ser evitados para realocação de epífitos, considerando seu curto tempo de vida.

Os dados registrados para $R$. lindbergiana e $R$. pachyptera quanto à formação de raízes estão de acordo, de modo geral, com várias outras espécies de cactáceas, sugerindo que a família pode apresentar bons resultados quando houver necessidade de realocação de indivíduos para novas áreas. Apesar de a pesquisa ter sido conduzida com espécies distintas, Duarte \& Gandolfi (2017) registraram valores semelhantes de sobrevivência para cactáceas transplantadas para duas áreas de Floresta Estacional Semidecidual em regeneração, no estado de São Paulo. Os autores observaram elevadas porcentagens de fixação das espécies Rhipsalis floccosa Salm-Dyck ex Pfeiff. (86,2\% e 93,3\%) e Lepismium cruciforme $(62,1 \%$ e $96,7 \%)$ após um ano de transplante em florestas restauradas a 23 e 13 anos, respectivamente. No entanto, neste mesmo estudo, R. floccosa não apresentou brotação no período. Jasper et al. (2005) também avaliaram espécies de cactáceas transplantadas para o ecótono da Floresta Estacional Decidual e Floresta Ombrófila Mista, no Rio Grande do Sul, obtendo resultados positivos na sobrevivência da maior parte delas. Os autores observaram brotamento em $L$. cruciforme (Vell.) Miq. e L. lumbricoides (Lem.) Barthlott após 10 meses de realocação das cactáceas. Milaneze-Gutierre et al. (2017), ao contrário, afirmaram que as cactáceas foram os epífitos mais sensíveis ao replantio dentre as várias famílias resgatas pelas equipes na UHE Mauá, PR.

A mortalidade foi maior para as duas espécies nos primeiros seis meses após a implantação na floresta (Tabelas 3 e 5), sugerindo que assim que os fragmentos de cladódios formam raízes, as suas chances de sobrevivência, e consequente desenvolvimento, aumentam. Exceção deve ser dada ao lote de $R$. lindbergiana instalado na estação das chuvas, cuja mortalidade se estendeu ao longo da experimentação, provavelmente como efeito da diminuição da precipitação no período que sucedeu a implantação, além da condição de estresse proporcionada pela realocação.

A distinta formação de raízes em ambas as espécies (Figuras 8 e 9), prontamente após implantação em campo, está de acordo com os resultados obtidos em casa de vegetação (Tabelas 1 e 2), onde também se pôde registrar raízes na maioria dos fragmentos após um mês de experimentação, independente dos substratos. A formação de raízes nas espécies estudadas está relacionada com a habilidade de cactáceas epifíticas produzirem raízes adventícias ao longo dos cladódios, utilizadas na absorção de água e minerais e também na sua ancoragem nos substratos (Wallace \& Gibson, 2002).

Nas cactáceas estudadas, a expedita formação de raízes parece ser uma estratégia de sobrevivência muito eficiente, inclusive com a formação de raízes na porção em contato ou próximas a um substrato, como o ritidoma das árvores ou o substrato da bandeja. Essa característica descrita para a família (Anderson, 2001) aumenta a probabilidade de sucesso na fixação e absorção de nutrientes e água. As raízes surgiram nas extremidades e ao longo dos fragmentos dos cladódios nas duas espécies (Figuras 8 e 9), complementando a ideia da necessidade de colocar a planta em contato com o ritidoma das árvores que deverão servir como suporte. Este procedimento aumenta as chances de sucesso de realocação de cactáceas, e pode ser realizado de maneira simples, com poucos investimentos. Os materiais necessários resumem-se a fitas de amarração, o que implica em baixo custo financeiro, além do pouco tempo necessário para implantação, principalmente se as árvores suporte não forem altas.

Destaca-se que, mesmo com a fixação de quatro fragmentos de cactáceas em cada árvore de $M$. polymorphum (árvores suporte), tendo sido o lote de $R$. lindbergiana instalado em 2011 e o de R. pachyptera em 2012, não se observou qualquer indicação de facilitação ou mesmo competição entre os indivíduos e/ou espécies. $\mathrm{Na}$ instalação, a escolha da posição de fixação nos suportes considerou essa possibilidade, afastando os fragmentos uns dos outros, visto que a interação entre indivíduos epifíticos é conhecida e presumida em ambientes naturais, como bem discutido, por exemplo, por Hernandez-Rosas (2001).

A formação de ramos apical e lateral em $R$. pachyptera ocorreu com mais frequência na união dos dois artículos e na extremidade do artículo mais jovem (Figura 9B), 
o que era esperado para a espécie (Zappi et al., 2007). Neste sentido, vale destacar a importância de se observar a posição de fixação do fragmento, na instalação das plantas de $R$. pachyptera nas árvores da floresta em regeneração, é importante observar a posição de fixação do fragmento. Considerando que os ramos surgiram frequentemente na extremidade do artículo mais jovem ou na articulação entre os dois artículos (Figuras 5 e 9), a fixação do fragmento com o artículo mais jovem posicionado para o alto foi, provavelmente, um equívoco. Os ramos, à medida em que se desenvolviam, foram se curvando e assumindo um posicionamento desfavorável para a estabilidade da planta, pois de uma posição inicial ereta, passaram a pender em direção ao solo. Neste contexto, alguns indivíduos que formaram até 17 novos artículos, demonstraram instabilidade ao ter que suportar peso excessivo, sugerindo a possibilidade de futuro desprendimento das árvores suporte, posto que as fitas utilizadas para fixação se decompõem ao longo do tempo. No entanto, a queda não foi constatada até o final da experimentação. Neste sentido, sugere-se testar a fixação dos artículos de $R$. pachyptera na árvore de modo inverso, ou seja, com o artículo mais antigo para cima e o mais jovem para baixo. Assim, com a brotação dos ramos a partir do artículo mais jovem, o peso será mais bem distribuído, diminuindo o risco de perda do fragmento realocado. Os comprimentos médios dos ramos do lote de chuva (51,5 cm em 24 meses) e do lote de seca (46,6 cm aos 18 meses de experimentação), ratifica o bom desenvolvimento da espécie, pois representam praticamente o dobro do tamanho dos artículos realocados $(30 \mathrm{~cm})$. Associando-se às altas taxas de sobrevivência de $R$. pachyptera, tem-se clara indicação de que a espécie cresceu muito bem depois de ter sido fixada ao novo suporte.

Os ramos de $R$. lindbergiana cresceram em várias posições dos fragmentos realocados, surgindo inclusive em grupos de 2-3 ramos em uma mesmo ponto (Figura 6), o que é descrito para a espécie (Taylor \& Zappi, 2004). Eles alcançaram, no lote de seca e após 30 meses de experimentação, a média de 22,8 ramos por indivíduo e 1,7 m de comprimento. Em outras palavras, por meio da fixação de pequenos fragmentos de aproximadamente $20 \mathrm{~cm}$, após o período pouco maior que dois anos, obteve-se indivíduos com dimensões relevantes, os quais atraíram insetos polinizadores, aves que consumiam seus frutos, lagartas que se alimentavam dos cladódios e insetos que utilizavam os cladódios para construir ninhos, todas interações observadas nessa área de estudos. Diferente dos resultados obtidos por Duarte \& Gandolfi (2013), que discutem o porte dos indivíduos de Aechmea bromeliifolia (Rudge) Baker que devem ser realocados, as cactáceas estudadas podem ser utilizadas na forma de fragmentos para o processo de restauração ecológica, aumentando o rendimento do material biológico e facilitando as atividades de organização e implantação em campo.

Os dados mostram que é possível realocar e implantar indivíduos de $R$. lindbergiana e $R$. pachyptera, ou fragmentos deles, sem qualquer necessidade de proteção do cladódio contra a pressão, e possível dano, da fita de amarração, apenas colocando-as em contato direto com fustes e galhos de árvores. As espécies são bastante rústicas e suas brotações são expressivas, principalmente quando a planta fica em contato direto com o substrato. Essa mesma técnica pode ser testada com outros epífitos nativos, de preferência aqueles mais comuns de cada região, observados usualmente a pleno sol, sendo estes os mais indicados para iniciar enriquecimentos de áreas mais abertas. Mesmo que os ambientes não sejam muito semelhantes aos ambientes de origem, como também afirmam Jasper et al. (2005), os epífitos mais comuns, desde que nativos, com maior plasticidade na adaptação a diferentes condições abióticas, podem ser introduzidos em florestas em regeneração e em florestas de margens de rios que são protegidas pela legislação brasileira.

O emprego dessas espécies pode ser recomendado para impulsionar o processo de recuperação da biodiversidade e funcionalidade ecológica de áreas com suportes arbóreos. Ela pode ser realizada através da realocação de indivíduos oriundos de resgate, garantindo um bom aproveitamento do material biológico que seria perdido com a supressão de florestas, em cumprimento à legislação ambiental brasileira, mas também pela multiplicação do material através da simples fragmentação das cactáceas e fixação nos suportes.

\section{Conclusões}

A estação do ano com maior precipitação interfere de modo positivo na sobrevivência e o desenvolvimento de Rhipsalis lindbergiana, relação não registrada para R. pachyptera. De qualquer maneira, sugere-se, para a região de estudo, que as cactáceas sejam realocadas ao final da estação seca ou início da estação chuvosa, para que as plantas se beneficiem com as chuvas, já 
com as raízes formadas e, assim, se desenvolvam com mais vigor.

As dimensões das árvores suporte foram importantes para o sucesso na sobrevivência e desenvolvimento de $R$. lindbergiana, evidenciando a importância em selecionar forófitos de porte maior para realocação de cactáceas e, provavelmente, de várias outras espécies epifíticas, sendo necessárias mais pesquisas com estas plantas em áreas de restauração.

A sobrevivência de $R$. lindbergiana e $R$. pachyptera foi alta, independente do substrato das bandejas em casa de vegetação. Mas para o crescimento e desenvolvimento de ambas as espécies, foi o composto orgânico que gerou os melhores resultados, sendo o substrato mais indicado em casa de vegetação.

É importante que os fragmentos das cactáceas estudadas, quando fixados nas árvores suporte, estejam efetivamente em contato com o tronco, para desencadear o processo de formação das raízes, fixação ao substrato e desenvolvimento das plantas.

A técnica de realocação de $R$. lindbergiana e $R$. pachyptera é simples, com baixos custos de implantação. Essas podem embasar práticas bem-sucedidas de realocação de outras cactáceas, além de enriquecer áreas em processo de restauração, pois sobrevivem e se desenvolvem, de modo geral, independente das condições climáticas.

\section{Agradecimentos}

Aos funcionários da empresa Dédalos, contratada da Petrobras, que muito auxiliaram nos trabalhos em campo, à Embrapa Florestas e Embrapa Agrobiologia, além dos revisores do trabalho pelas valiosas sugestões.

\section{Referências}

Ana. Agência Nacional de Águas. Hidroweb: sistemas de informações hidrológicas. Disponível em: < http://www.snirh.gov. br/hidroweb/>. Acesso em: 21 nov. 2018.

Anderson, E. F. The cactus family. Oregon: Timber Press, 2001. $776 \mathrm{p}$.

Barthlott, W. \& Hunt, D. R. Cactaceae. In: Kubitzki, K. (Ed.). The families and genera of vascular plants. Berlin: Springer-Verlag, 1993. v. 2. p. 161-197.

Bonnet, A. et al. Relações de bromeliáceas epifíticas com fatores ambientais em planícies de inundação do rio Iguaçu, Paraná, Brasil. Floresta, v. 40, n. 1, p. 193-208, 2010. http://dx.doi.org/10.5380/ rf.v40i1.17110
Bonnet, A. et al. Epífitos vasculares e sua distribuição na paisagem. In: Prado, R. B. et al. (Ed.). Monitoramento da revegetação do COMPERJ: etapa inicial. Brasília, DF: Embrapa, 2014. p. 263-277.

Calvente, A. D. M. et al. Listagem, distribuição geográfica e conservação das espécies de Cactaceae no estado do Rio de Janeiro. Rodriguésia, v. 56, n. 87, p. 141-162, 2005. http://dx.doi. org/10.1590/2175-78602005568711.

Collet, D. Modeling binary data. London: Chapman \& Hall, 1991. $369 \mathrm{p}$.

Curcio, G. R. et al. Compartimentação das paisagens. In: Prado, R. B. et al. (Ed.). Monitoramento da revegetação do COMPERJ: etapa inicial. Brasília, DF: Embrapa, 2014. p. 23-36..

Duarte, M. M. \& Gandolfi, S. Enriquecimento de florestas em processo de restauração: aspectos de epífitas e forófitos que podem ser considerados. Hoehnea, v. 40, n. 3, p. 507-514, 2013. http:// dx.doi.org/10.1590/S2236-89062013000300010.

Duarte, M. M. \& Gandolfi. S. Diversifying growth forms in tropical forest restoration: enrichment with vascular epiphytes. Forest Ecology and Management, v. 401, p. 89-98, 2017. https://doi. org/10.1016/j.foreco.2017.06.063.

Garcia, L. C. et al. Restoration over time: is it possible to restore trees and non-trees in high-diversity forests? Applied Vegetation Science, v. 19, n. 4, p. 655-666, 2016. https://doi.org/10.1111/avsc.12264

Gonçalves, A. O. Caracterização climática. In: Prado, R. B. et al. (Ed.). Monitoramento da revegetação do COMPERJ: etapa inicial. Brasília, DF: Embrapa, 2014. p. 65-81.

Gentry, A. H. \& Dodson, C. H. Diversity and Biogeography of Neotropical Vascular Epiphytes. Annals of the Missouri Botanical Garden, v. 74, p. 205-233, 1987.

Hernandez-Rosas, J. Ocupación de los portadores por epifitas vasculares em um bosque húmedo tropical del alto Orinoco, Edo. Amazonas, Venezuela. Acta Científica Venezolana, v. 52, n. 4, p. 292-303, 2001.

Ibama. Instrução Normativa $n^{\circ}$ 6, de 7 de abril de 2009. Diário Oficial [da] República Federativa do Brasil, Brasília, DF, n. 67, p. 82,8 abr. 2009.

IBGE. Manual técnico da vegetação brasileira. 2 ed. Rio de Janeiro: IBGE, 2012. 271p. (IBGE. Manuais técnicos em geociências).

Jakovac, A. C. C. et al. Epiphytes transplant to improve the diversity on restored areas. In: SIMPOSIO INTERNACIONAL SOBRE RESTAURACIÓN ECOLÓGICA, 2., 2007, Cuba. Annalles... Cuba: Grupo Cubano de Restauración Ecológica, 2007. p. 207.

Jasper, A. et al. Metodologia de salvamento de Bromeliaceae e Orchidaceae na pequena central Hidrelétrica (PCH) Salto Forqueta - São José do Herval/Putinga - RS - Brasil. Pesquisas, Botânica, v. 56, p. 265-284, 2005.

Marcusso, G. M. et al. Epiphyte-phorophyte relationships: assessing the differences between Seasonal Semideciduous and Swamp Forests in Southeastern Brazil. Hoehnea, v. 46, n. 2, e232018, 2019. http:// dx.doi.org/10.1590/2236-8906-23/2018.

McCullagh, P. \& Nelder, J. A. Generalized linear models. 2. ed. London: Chapman \& Hall, 1989. 511 p. 
Mielniczuk, J. Matéria orgânica e a sustentabilidade de sistemas agrícolas. In: Santos, G. de A. et al. (Ed.) Fundamentos da matéria orgânica do solo: ecossistemas tropicais \& subtropicais. Porto Alegre: Metrópole, 2008. p. 1- 4.

Milaneze-Gutierre, M. A. et al. Resgate e replantio de epífitas da Usina Hidrelétrica Mauá, estado do Paraná. In: Milaneze-Gutierre, M. A. et al. (Org.). Resgate de epífitas da Usina Hidrelétrica Mauá. Maringá: Massoni, 2017. p. 11-40.

Nadkarni, N. M. \& Solano, R. Potential effects of climate change on canopy communities in a tropical cloud forest: an experimental approach. Oecologia, v. 131, p. 580-586, 2002.

Nieder, J. et al. Epiphytes and their contribution to canopy diversity. Plant Ecology, v. 153, n. 2, p. 51-63, 2001.

Prado, R. B. et al. (Ed.). Monitoramento da revegetação do COMPERJ: etapa inicial. Brasília, DF: Embrapa, 2014. 350 p.

Resende, A. S. de et al. As mudas para o Comperj. In: Resende, A. $\mathrm{S}$. de et al. (Org.). Complexo petroquímico do Rio de Janeiro: produção de mudas de espécies arbóreas nativas e suas relações ambientais no "Corredor Ecológico Comperj". Colombo: Embrapa Florestas, 2009. p. 66-75.
Rocha, C. F. D. et al. Conservando uma larga proporção da diversidade biológica através da conservação de Bromeliaceae. Vidalia, v. 2, p. 52-68, 2004.

Santos Junior, N. A. dos \& Tamaki, V. Realocação de plantas resgatadas em processos de supressão da vegetação: uma ação do Projeto Rodoanel Trecho Norte/SP. In: REUNIÃO ANUAL DE BOTÂNICA, 21., 2014, São Paulo. Anais... São Paulo: Instituto de Botânica, 2014. p. 1-4.

Stell, R. G. D. \& Torrie, J. H. Principles and procedures of statistics: a biometrical approach. New York: MacGraw-Hill, 1980. $633 \mathrm{p}$.

Stevenson, F. J. Humus chemistry: genesis, composition, reactions. New York: J. Wiley, 1994. 496 p.

Taylor, N. P. \& Zappi, D. C. Cacti of eastern Brazil. Richmond, Surrey: Royal Botanic Gardens, 2004. 499 p.

Wallace R. S. \& Gibson A. C. Evolution and systematics. In: Nobel, P. S. (Ed.). Cacti: Biology and uses. Los Angeles: University of California Press, 2002. p. 125-141.

Zappi, D. C. et al. Cactaceae. In: Wanderley, M. G. L. et al. (Ed.). Flora fanerogâmica do Estado de São Paulo. São Paulo: Instituto de Botânica, 2007. v. 5. p. 163-193. 